\title{
Deteksi Microaneurysm pada Mata sebagai Langkah Awal untuk Penentuan Diabetic Retinophaty menggunakan Pengolahan Citra Digital
}

\author{
Anisa Habsari ${ }^{1 *}$, Tri Harsono ${ }^{2 *}$, Heny Yuniarti ${ }^{3 *}$, Rita Tjandra ${ }^{4}$ \\ *Teknik Komputer, Politeknik Elektronika Negeri Surabaya \\ habsarianisa13@gmail.com ${ }^{2}$, trison@pens.ac.id ${ }^{2}$, heny@pens.ac.id $^{3}$, $\underline{\text { ritatjandraspm@gmail.com}}^{4}$
}

\begin{tabular}{l} 
Article Info \\
\hline Article history: \\
Received 2021-08-26 \\
Revised 2021-09-16 \\
Accepted 2021-09-28 \\
\hline
\end{tabular}

Keyword:

Detection,

Diabetic Retinopathy,

Digital Image Processing,

Microaneurysm.

\begin{abstract}
Diabetic Retinopathy is a microvascular complication of diabetes mellitus. According to WHO (World Health Organization), there are more than 347 billion people who suffer from diabetes. This disease will become the seventh leading cause of death in the world in 2030. Based on research in Indonesia, it is estimated that there are $42.6 \%$ of diabetic retinopathy. Therefore, this work plans a system to assist medical doctors in identifying diabetic retinopathy through its characteristics, namely microaneurysm. This system begins with an input retinal image from the fundus camera. Then the input will be processed in preprocessing to increase the contrast using the green channel. The next stage is segmentation. This is used to detect candidates from blood vessels and microaneurysms that use morphology operations. The next step is feature extraction, where it uses the features of GLCM (Gray Level Co-occurrence Matrix) and white pixels detected in the image resulting from segmentation. The value of the white pixels and the values in the GLCM feature are used as parameters in determining whether the classification process will be used as a determination of a Diabetic Retinopathy image or not. The success rate of the system using the SVM (Support Vector Machine) method in identifying microaneurysm is $88.4 \%$.
\end{abstract}

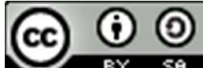

This is an open access article under the CC-BY-SA license.

\section{Pendahuluan}

Diabetik Retinopati merupakan penyakit mata yang diderita oleh penderita diabetes mellitus. Penyakit ini dapat menyebabkan kebutakan dan sering diderita pada usia 20-74 tahun. Kelainan patologik yang paling awal dikenali adalah penebalan membran basal endotel kapiler dan berkurangnya jumlah perisit. Kapiler tersebut akan membentuk kantungkantung kecil menonjol seperti titik-titik yang sering disebut microaneurysm [1].

Diabetik Retinopati adalah penyakit komplikasi mikrovaskular dari diabetes mellitus dengan angka prevalensi yang cukup tinggi. Berdasarkan data penelitian di Indonesia, diperkirakan terdapat $42,6 \%$ diabetik retinopati. Hal ini dapat diartikan ada kemungkinan ditemukannya paling sedikit 24.600 orang dengan diabetik retinopati dan setidaknya $10 \%$ dari jumlah tersebut mengalami kebutaan. Estimasi jumlah akan terus meningkat pada tahun 2030 dengan jumlah sekitar 98.400 orang akan menderita diabetes dan sebanyak 11.000 diantaranya akan mengalami kebutaan.
Berdasarkan estimasi tersebut maka diperlukan pencegahan dan deteksi dini agar dapat ditangani dengan baik [2].

Penelitian lain yang dilakukan oleh Vineeta Das, N,B. Puhan, dan Rashmi Panda mengenai deteksi microaneurysm dengan menggunakan entropy threshlolding. Algoritma yang diusulkan dalam penelitian ini juga memiliki empat tahapan besar yaitu preprocessing, matched filter, entropy based thresholding, dan Naïve Bayes Classification. Hasil penelitian ini yaitu nilai shannon entropy yang menunjukkan maksimum sensitivitas 58.28\% di False Positive. Metode yang digunakan perlu ditingkatkan dalam mendeteksi MA yang sulit dilihat [3].

Penelitian yang dilakukan oleh Shailesh Kumar dan Basant Kumar meneliti microaneurysm yang terdapat pada kamera fundus. Deteksi Diabetic Retinopathy melalui tahapan yaitu preprocessing, features extraction, dan classification SVM (Support Vector Machine). Penelitian ini menghasilkan hasil yang cukup akurat dimana nilai dari sensitifitas $96 \%$ dan spesifik mencapai 92\%. Penelitian ini 
menyarankan untuk lebih mempertimbangkan keabnormalan dari pembuluh darah [4].

Evaluasi klinis yang dilakukan dokter dalam mendeteksi Diabetik Retinopati yaitu melalui kamera fundus maupun pemeriksaan langsung melalui ophthalmoscope. Terdapat beberapa citra yang sulit dideteksi secara visual oleh dokter dikarenakan intensitas warna yang memiliki kemiripan dengan object lain [1]. Pengamatan secara visual yang dilakukan dokter terkadang memerlukan waktu yang lama sehingga untuk menentukan tindakan lanjut dari penderita diabetik retinopati juga semakin lama.

Sistem yang dibuat pada penelitian ini diharapkan dapat membantu dokter dalam melakukan diagnosis penyakit Diabetic Retinopathy dengan karakteristik microaneurysm sehingga dokter dapat dengan cepat dan tepat menangani penderita. Input sistem berupa citra retina dari kamera fundus. Sistem mendeteksi microaneurysm [5] dan dapat menyebabkan pendarahan intra retina, sebagai indikator awal yang muncul pada penyakit Diabetic Retinopathy kemudian diakhir sistem dapat menentukan sebuah citra retina dari kamera fundus tersebut normal atau teridentifikasi sebagai citra Diabetic Retinopathy.

\section{LITERATUR}

Metode-metode yang digunakan dalam mengembangkan penelitian ini diuraikan sebagai berikut:

A. Diagram Sistem

Sistem yang dibuat memiliki beberapa proses yang diperlihatkan dengan gambar 1 .

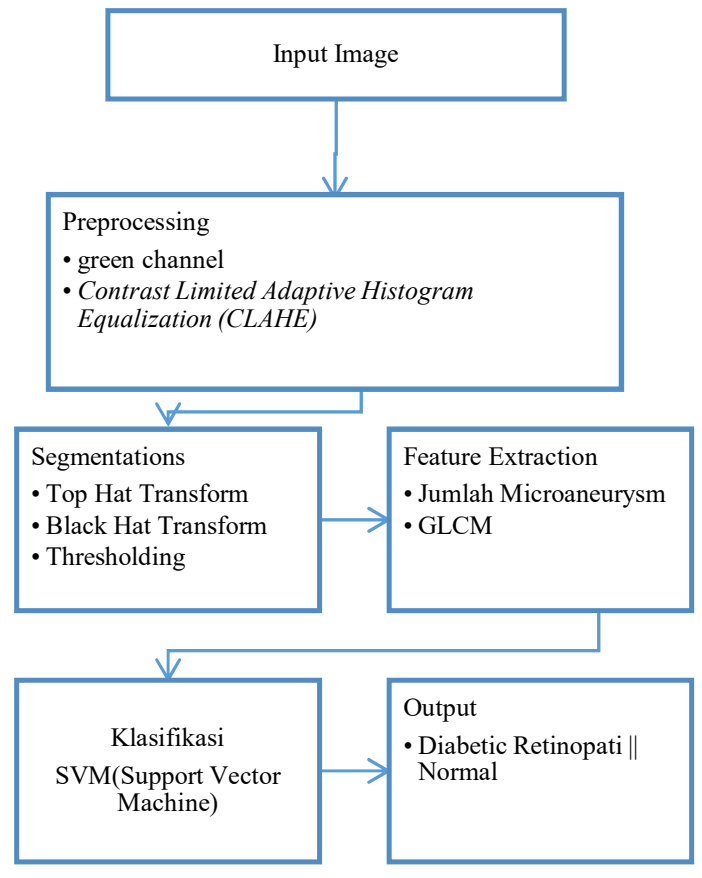

Gambar 1. Diagram Rancangan Sistem

Gambar 1 merupakan rancangan sistem yang digunakan. Tahapan input image merupakan tahapan untuk memasukkan citra ke dalam sistem. Citra yang digunakan berupa citra retina yang berasal dari kamera fundus dengan format .jpg. Citra input akan diperjelas dengan menggunakan Contrast Limited Adaptive Histogram Equalization (CLAHE). Citra akan diperjelas guna mempermudahkan dalam proses segmentasi. Proses Segmentation digunakan untuk mengetahui calon Microaneurysm dan blood vessel untuk diidentifikasi pada proses berikutnya. Metode yang digunakan adalah Top Hat Transform, kemudian metode black hat transform digunakan untuk mengidentifikasi blood vessel. Masing-masing citra hasil dari proses top-hat transform dan black-hat transform akan di-thresholding kembali. Tahapan pada feature extraction merupakan sebuah tahapan untuk mengekstraksi fitur maupun ciri-ciri microaneurysm pada citra. Dalam penelitian ini digunakan ekstraksi ciri dengan GLCM (Gray Level Co-occurrence Matrix) dan fitur microaneurysm. Fitur microaneurysm diperoleh dari jumlah total piksel putih dalam citra. Jumlah piksel putih yang dihasilkan dalam proses segmentasi digunakan sebagai ciri yang berfungsi sebagai penentu ciri mata yang teridentifikasi sebagai citra yang sehat, maupun citra yang berpotensi sebagai citra diabetic retinopathy. Proses klasifikasi sistem akan dilakukan dengan Support Vector Machine (SVM) dimana sistem akan dilatih dengan beberapa jumlah data yang memiliki perbedaan fitur-fitur hasil dari tahapan ekstraksi fitur untuk mempelajari dan mendapatkan model dalam pengklasifikasiannya. Langkah berikutnya data akan diuji dan diklasifikasikan menjadi dua kelas, yaitu citra normal dan citra diabetic retinopathy.

\section{B. Penyakit Diabetic Retinopathy}

Diabetic Retinopathy merupakan suatu kelainan mata yang disebabkan oleh diabetes. Secara umum orang yang menderita diabetes memiliki kadar gula yang tinggi sehingga aliran darah menyebabkan kerusakan pada indera penglihatan.

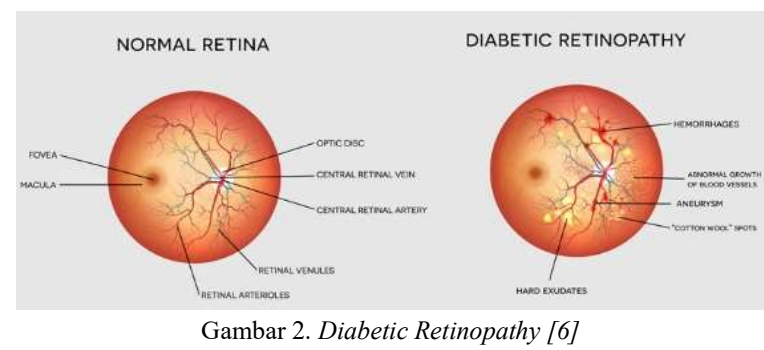

Diabetic retinopathy terdapat dua jenis yaitu Non Proliferasi Diabetc Retinopathy (NPDR) dan Proliferasi Diabetic Retinopathy (PDR). NPDR merupakan tipe dari Diabetic Retinopathy dimana mengalami kelemahan pada pembuluh darah retina. Beberapa kasus menyebutkan bahwa kapiler terdapat cairan dan akan terjadi pembocoran darah pada retina. Diameter pembuluh darah akan membesar dan tepi pembuluh berbentuk tidak teratur. NPDR data berubah menjadi PDR dimana PDR mengakibatkan pertumbuhan 
pembuluh darah baru yang tidak normal pada retina sehingga menyebabkan gangguan pada aliran cairan normal pada mata. Beberapa karakteristik yang dapat ditemukan saat tahap NPDR [1] yaitu:

1. Microaneuryms, sebuah kapiler kantung-kantung kecil menonjol seperti titik-titik.

2. Exudate, sesuatu yang keluar dari luka, cairan luka atau kelebihan cairan normal tubuh.

3. Hemorrhages, suatu pendarahan yang terjadi di retina.

\section{Microaenursm}

Microaneurysm merupakan kapiler yang membentuk kantung-kantung kecil menonjol sepeti titik-titik. Tahapan awal dari Diabetic Retinopathy adalah melemahnya pembuluh darah sehingga menyebabkan kebocoran dan membentuk titik-titik pendarahan yang disebut microaneurysm [1].

\section{Contrast Limites Adaptive Histogram Equalization (CLAHE)}

CLAHE (Contrast limited Adaptive Histogram Equalization) adalah suatu metode yang digunakan untuk mengatasi keterbatasan standard pemetaan histogram pada suatu citra, merupakan metode lanjutan dari Adaptive histogram Equalization (AHE). Kedua metode ini berfungsi untuk meningkatkan kualitas citra agar menghasilkan citra yang baik sebagai pemberi informasi yang sesuai tujuan dari image processing [7]

\section{E. Median Filtering}

Median filter merupakan salah satu dari filtering nonlinier yang berfungsi mengurutkan nilai intensitas sekumpulan piksel dan mengganti nilai piksel tersebut ke nilai mediannya. Median filter pada dasarnya difungsikan sebagai penghalus dan mengurangi noise atau gangguan yang terdapat pada citra [7]

\section{F. Thresholding}

Thresholding merupakan sebuah proses dimana menggunakan nilai batas(threshold) dalam mengubah nilai piksel yang terdapat pada citra greyscale menjadi suatu citra berwarna hitam putih. Proses kerja dari thresholding adalah ketika suatu citra memiliki nilai greyscale yang lebih besar dari nilai threshold, maka piksel tersebut akan berganti nilai menjadi 1 atau berwarna putih. Namun, apabila suatu citra grayscale memiliki nilai piksel yang lebih kecil daripada threshold makan citra tersebut akan berubah nilai menjadi 0 atau berwarna hitam.

\section{G. GLCM (Gray Level Co-occurrence Matrix)}

Gray Level Co-occurrence Matrix merupakan metode ekstraksi fitur yang berbasis tekstur. GLCM (Gray Level Cooccurrence Matrix) melakukan penentuan hubungan tekstur antara piksel dengan cara operasi berdasarkan orde kedua statistik dalam gambar. Properti GLCM suatu gambar dinyatakan sebagai matriks yang memiliki baris dan kolom serupa dengan nilai abu-abu pada gambar. Elemen matriks tersebut bergantung pada frekuensi dari kedua piksel yang ditentukan [8].

GLCM memiliki beberapa fitur yang digunakan [9]. Fiturfitur tersebut antara lain: energi, kontras, homogenitas inverse difference moment, entropi, dan mean. Energi adalah fitur yang digunakan untuk mengukur tingkat dari piksel dengan ukuran ketidakteraturan dalam tekstur suatu gambar sedangkan kontras adalah ukuran spasial frekuensi gambar intensitas piksel dan sekitarnya pada suatu gambar. Kontras dihitung berdasarkan perbedaan warna dan kecerahan setiap objek dengan objek lain dalam satu bidang pandang yang sama. Homogenitas adalah fitur yang digunakan untuk mengukur homogenitas variasi suau intensitas gambar. Inverse Difference Moment (IDM) adalah lokal homogenitas yang dihitung ketika nilai tingkat keabuan local sama dan inversi GLCM bernilai tinggi. Entropi adalah fitur yang berfungsi untuk mengatur keseragaman antara piksel dalam gambar dan keacakan yang digunakan untuk mengkarakteristikan tekstur gambar. Mean adalah fitur dengan jumlah rata-rata yang mengukur distribusi jumlah tingkat keabuan dalam suatu gambar.

\section{H. Morphology Operation}

Transformasi morfologi merupakan kumpulan dari operasi sederhana berdasarkan bentuk citra. Input dari proses ini membutuhkan dua input, original images dan structuring element atau kernel yang menentukan sifat operasi. Dua operator morfologi dasar yaitu erosi dan dilasi. Operasioperasi morfologi [10] diantaranya adalah sebagai berikut:

1) Operasi erosi memiliki konsep yaitu mengikis batasbatas foreground. Sebuah piksel dalam gambar asli akan dianggap 1 hanya jika semua piksel di bawah kernel adalah 1, jika tidak maka akan terkikis (berubah 0). Hal ini menyebabkan semua piksel didekat batas akan dibuang berdasarkan ukuran kernel.

2) Operasi dilatasi merupakan operasi yang memiliki elemen piksel bernilai 1. Hal ini menyebabkan jika setidaknya terdapat satu piksel dibawah kernel adalah satu, maka hal ini dapat menyebabkan meningkatnya white region atau ukuran dari foreground juga akan bertambah.

3) Operasi opening merupakan operasi dengan gabungan proses antara erosi yang kemudian diikuti dilatasi.

4) Operasi closing dimulai dengan operasi dilatasi dan diikuti dengan operasi erosi. Hal ini berfungsi untuk menutup lubang kecil didalam objek foreground atau titiktitik hitam pada object.

5) Operasi morfologi gradient merupakan operasi yang memperlihatkan perbedaan antara dilatasi dan erosi gambar.

6) Operasi top-hat transform merupakan operasi dengan menunjukkan perbedaan antara gambar input dengan opening images. 
7) Proses operasi black hat transform merupakan suatu proses dengan perbedaan antara gambar input dengan gambar hasil closing.

\section{Support Vector Machine (SVM)}

Support Vector Machine (SVM) pertama kali diperkenalkan kepada public oleh Vapnik tahun 1992 sebagai metode machine learning yang berkerja dengan prinsip Structural Risk Minimization (SRM) yang memiliki fungsi untuk menentukan hyperplane terbaik yang memisahkan dua class pada input space [11].

Metode SVM mengklasifikasikan kelas menjadi dua, dimana kelas pertama dipisahkan dengan hyperplane yang memiliki nilai 1 , sedangkan kelas lainnya memiliki nilai -1 .

Algoritma sequential training yang digunakan dalam Support Vector Machine adalah sebagai berikut:

a. Inisialisasi $\alpha_{1}=0$, kemudian akan diperhitungkan matrik Hessian. Matrik Hessian merupakan perkalian antara kernel polynomial dengan nilai $\mathrm{Y}$ yang berupa vector yang berisikan nilai 1 atau -1 . Inisialisasi ini digunakan untuk mencari nilai support vector.

b. Untuk setiap data akan dihitung dengan matrix Hessian

Tahapan tersebut akan diulang sehingga mendapatkan keadaan iterasi maksimum.

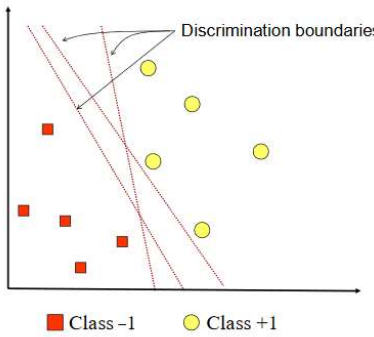

(a)

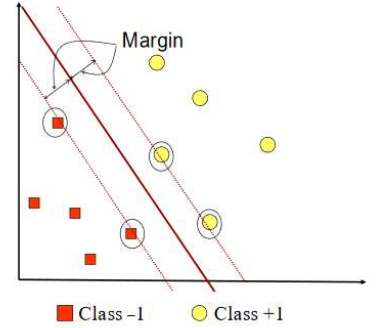

(b)
Gambar 3. Hyperplane terbaik yang memisahkan kedua kelas negatif dan positif [12]

Gambar 3 menunjukkan beberapa pattern yang menjadi bagian dari anggota dua kelas. Pattern yang tergabung dalam kelas -1 diberi symbol berwarna merah kotak, sedangkan kelas +1 diberikan symbol kuning lingkaran. Garis merah tebal pada gambar diatas (b) menunjukkan hyperplane terbaik yang berada ditengah-tengah kedua kelas dan memisahkan kedua kelompok tersebut. Sedangkan titik merah dan kuning yang berada didalam lingkaran hitam merupakan support vector [12].

\section{Metodologi Penelitian}

Implementasi sistem dilakukan dengan beberapa tahapan algoritma sistem. Citra retina dari kamera fundus akan digunakan sebagai input yang akan diproses dan dianalisis. Citra retina didapatkan dari Rumah Sakit Mata Undaan dan divalidasi oleh dokter ahli. Citra yang dinyatakan sakit akan mengandung microaneurysm sedangkan citra yang sehat adalah citra yang bersih tanpa adanya microaneurysm sebagai gejala awal penyakit diabetic retinopathy.

\section{A. Preprocessing}

Tahapan preprocessing merupakan tahapan yang digunakan untuk meningkatkan kualitas citra agar dapat diproses lebih baik pada sistem. Dalam meningkatkan kualitas citra dari gambar retina, diperlukan beberapa komponen yang dibuang sebelum diproses seperti Red Channel maupun Blue Channel dalam penelitian ini. Green Channel dikatakan memiliki kualitas terbaik dimana pada metode ini akan terlihat lebih jelas fitur dari microaneurysm dan blood vessel. Oleh karena itu, komponen yang diambil dari data masukan adalah green channel, sedangkan komponen warna lain akan dihilangkan. Hasil dari green channel kemudian diubah kedalam grayscale.

Contrast Limites Adaptive Histogram Equalization (CLAHE) merupakan sebuah teknik yang berfungsi untuk meningkatkan kualitas citra agar menghasilkan citra yang baik. Algoritma ini berfungsi untuk meningkatkan kontras suatu citra.

\section{B. Segmentasi}

Tahapan segmentasi terdiri dari beberapa tahapan umum yaitu segmentasi citra pembuluh darah dan calon microaneurysm, segmentasi pembuluh darah, serta hasil dari subtraksi kedua hasil citra segmentasi. Tahapan-tahapan tersebut terdiri dari beberapa metode. Metode yang digunakan untuk melakukan segmentasi blood vessel dan calon kandidat dari microaneurysm menggunakan top-hat transform. Top-Hat Transform merupakan metode dari operasi morfologi dimana metode ini menunjukkan perbedaan antara input citra dan operasi morfologi opening. Operasi opening merupakan operasi dengan gabungan proses antara erosi yang kemudian diikuti dilatasi. Hasil dari proses ini kemudian akan dilakukan proses thresholding.

Selanjutnya akan dilakukan proses segmentasi untuk mendapatkan fitur dari blood vessel. Langkah-langkah yang dilakukan adalah dengan metode median filtering untuk menghaluskan citra. Filter ini umumnya digunakan untuk mereduksi noise yang terdapat pada suatu citra guna meningkatkan kualitas citra dengan tetap mempertahankan edge dari citra tersebut. Median filtering diterapkan melalui setiap elemen dari input dan mengganti setiap piksel dengan median piksel sekitar piksel yang dievaluasi. Kemudian akan dilakukan proses black hat transform. Black-Hat transform merupakan salah satu operasi morfologi dimana ia menunjukkan perbedaan input dengan operasi closing. Operasi closing merupakan operasi morfologi dimana proses dilatasi akan diikuti dengan proses erosi. Hasil dari proses ini kemudian dilakukan thresholding.

Langkah selanjutnya adalah subtraction dari hasil segmentasi pertama yaitu segmentasi calon kandidat microaneurysm dan blood vessel, dengan hasil segmentasi yang kedua. Hal ini berfungsi untuk mendapatkan 
microaneurysm dan blood vessel yang memiliki warna sama yaitu merah. Image Subtraction atau pixel subtraction merupakan sebuah proses dimana nilai dari suatu digital, baik nilai numeric dari satu piksel maupun seluruh gambar akan dikurangkan dengan gambar lainnya. Proses subtraction dilakukan untuk menampilkan objek yang berwarna merah yang diidentifikasikan sebagai microaneurysm dan blood vessel.

\section{Feature Etraction}

Tahapan ekstraksi fitur dilakukan dengan beberapa tahapan yaitu perhitungan piksel putih yang akan diidentifikasi sebagai fitur citra serta perhitungan fitur dengan GLCM (Gray Level Co-occurrence Matrix). Fitur microaneurysm diperoleh dari jumlah total piksel putih dalam citra. Jumlah piksel putih yang dihasilkan dalam proses segmentasi, serta perhitungan GLCM berupa energy, kontras, homogenitas, IDM, entropi, dan mean digunakan sebagai ciri yang berfungsi sebagai penentu ciri mata yang teridentifikasi sebagai citra yang sehat, maupun citra yang berpotensi sebagai citra diabetic retinopathy.

\section{Klasifikasi}

Tahap klasifikasi menggunakan metode SVM (Support Vector Machine). Metode SVM menggunakan fitur-fitur yang berfungsi sebagai input. Fitur-fitur tersebut berasal dari hasil ekstraksi fitur berupa energy, contrast, homogeneity, IDM, entropy, Mean dan piksel putih yang terdeteksi dalam citra (microaneurysm). Output dari metode SVM yang digunakan adalah klasifikasi berupa citra normal maupun citra diabetic retinopathy.

\section{HASIL IMPLEMENTASI}

Implementasi sistem yang telah dilakukan menghasilkan hasil sistem yang dapat dilihat pada gambar 4 .

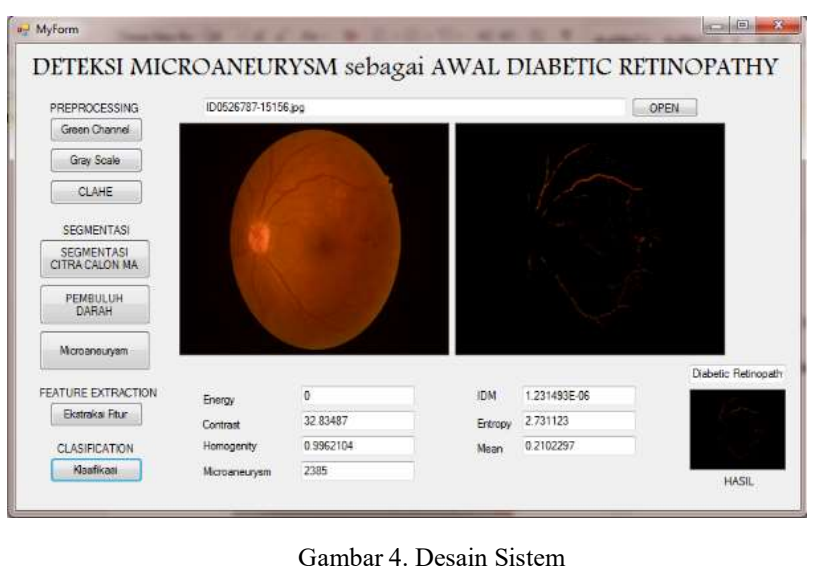

Sistem akan melakukan pengujian dengan beberapa tahapan. Pengujian sistem dilakukan dengan menguji semua data yang ada. Pengujian sistem ditunjukkan pada table I berikut ini.
TABEL I

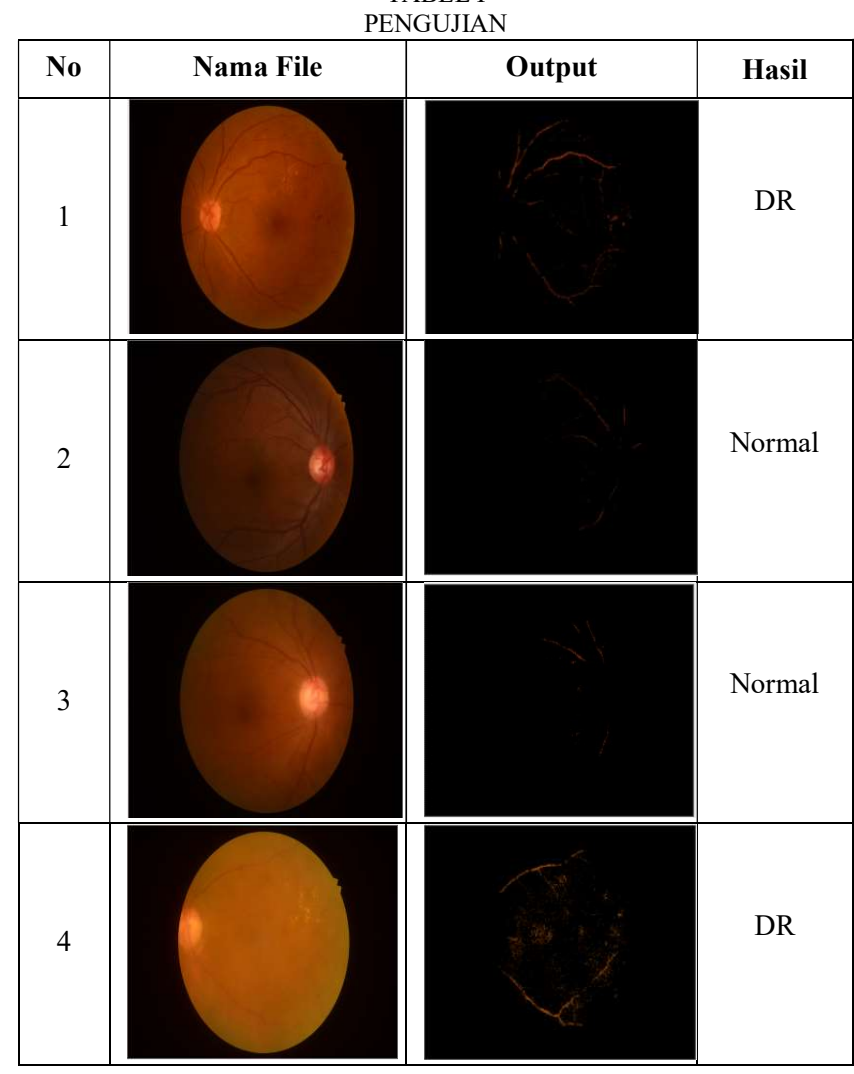

Sistem yang telah dibuat akan dihitung persentase akurasi maupun keberhasilan sistem. Tahap perhitungan error dilakukan sebagai proses untuk menghitung rata-rata error yang dilakukan berdasarkan hasil diagnosis yang dilakukan oleh sistem dengan hasil diagnosis yang dilakukan oleh rumah sakit. Perhitungan nilai rata-rata error diperhitungkan dengan melakukan perhitungan menggunakan persamaan matematika (1) berikut.

$$
\% \text { error }=\frac{\sum \text { data error }}{\sum \text { data seluruhnya }} \times 100 \%
$$

Persamaan 1 berfungsi sebagai persamaan matematika yang digunakan untuk menghitung persentase error dari sistem. Perhitungan persentase error dilakukan pada 30 data training dan 30 data testing. Hal ini bertujuan untuk menguji seberapa efektif sistem yang telah dibuat. Efektifitas sistem dilakukan dengan membandingkan hasil sistem dan hasil rumah sakit. Tabel II berikut merupakan hasil dari proses training. 
TABEL II

HASil Perhitungan ERror Data Training

\begin{tabular}{|c|c|c|c|c|}
\hline \multicolumn{5}{|c|}{ Hasil Perhitungan Error } \\
\hline \multirow[b]{2}{*}{ No } & \multirow[b]{2}{*}{ Nama File } & \multicolumn{2}{|c|}{ Hasil Diagnosis } & \multirow[b]{2}{*}{ Validasi } \\
\hline & & Sistem & $\begin{array}{c}\text { Rumah } \\
\text { sakit }\end{array}$ & \\
\hline 1 & $\begin{array}{c}\text { ID120054- } \\
\text { 12098.jpg }\end{array}$ & Normal & Normal & Benar \\
\hline 2 & $\begin{array}{l}\text { ID0739256- } \\
\text { 13969.jpg }\end{array}$ & Normal & Normal & Benar \\
\hline 3 & $\begin{array}{l}\text { ID742116- } \\
\text { 15274.jpg }\end{array}$ & Normal & Normal & Benar \\
\hline 4 & $\begin{array}{l}\text { ID0742246- } \\
\text { 15440.jpg }\end{array}$ & Normal & Normal & Benar \\
\hline 5 & $\begin{array}{c}\text { ID0742496- } \\
\text { 15779.jpg }\end{array}$ & Normal & Normal & Benar \\
\hline 6 & $\begin{array}{c}\text { ID0742796- } \\
\text { 15802.jpg }\end{array}$ & Normal & Normal & Benar \\
\hline 7 & $\begin{array}{c}\text { ID0742796- } \\
\text { 15805.jpg }\end{array}$ & Normal & Normal & Benar \\
\hline 8 & $\begin{array}{c}\text { ID0753645- } \\
\text { 9206.jpg }\end{array}$ & Normal & Normal & Benar \\
\hline 9 & $\begin{array}{c}\text { ID0234210- } \\
\text { 13570.jpg }\end{array}$ & DR & Normal & Salah \\
\hline 10 & $\begin{array}{l}\text { ID120054- } \\
\text { 12099.jpg }\end{array}$ & Normal & Normal & Benar \\
\hline 11 & $\begin{array}{c}\text { ID0777593- } \\
\text { 11613.jpg } \\
\end{array}$ & Normal & Normal & Benar \\
\hline 12 & $\begin{array}{c}\text { ID0779808- } \\
\text { 13049.jpg }\end{array}$ & Normal & Normal & Benar \\
\hline 13 & $\begin{array}{c}\text { ID0784321- } \\
\text { 11539.jpg }\end{array}$ & Normal & Normal & Benar \\
\hline 14 & $\begin{array}{l}\text { ID0784637- } \\
\text { 11501.jpg }\end{array}$ & Normal & Normal & Benar \\
\hline 15 & $\begin{array}{c}\text { ID0785335- } \\
\text { 11969.jpg }\end{array}$ & Normal & Normal & Benar \\
\hline 16 & $\begin{array}{c}\text { ID0233334- } \\
\text { 15743.jpg }\end{array}$ & $\begin{array}{c}\text { Diabetic } \\
\text { Retinopathy }\end{array}$ & $\begin{array}{c}\text { Diabetic } \\
\text { Retinopathy }\end{array}$ & Benar \\
\hline 17 & $\begin{array}{c}\text { ID0233334- } \\
\text { 15744.jpg } \\
\end{array}$ & $\begin{array}{c}\text { Diabetic } \\
\text { Retinopathy }\end{array}$ & $\begin{array}{c}\text { Diabetic } \\
\text { Retinopathy }\end{array}$ & Benar \\
\hline 18 & $\begin{array}{c}\text { ID0526787- } \\
\text { 15156.jpg }\end{array}$ & $\begin{array}{c}\text { Diabetic } \\
\text { Retinopathy }\end{array}$ & $\begin{array}{c}\text { Diabetic } \\
\text { Retinopathy }\end{array}$ & Benar \\
\hline 19 & $\begin{array}{c}\text { ID0676152- } \\
\text { 15948.jpg }\end{array}$ & $\begin{array}{c}\text { Diabetic } \\
\text { Retinopathy }\end{array}$ & $\begin{array}{c}\text { Diabetic } \\
\text { Retinopathy }\end{array}$ & Benar \\
\hline 20 & $\begin{array}{c}\text { ID0676152- } \\
\text { 15952.jpg }\end{array}$ & $\begin{array}{c}\text { Diabetic } \\
\text { Retinopathy }\end{array}$ & $\begin{array}{c}\text { Diabetic } \\
\text { Retinopathy }\end{array}$ & Benar \\
\hline 21 & $\begin{array}{c}\text { ID0714679- } \\
\text { 13821.jpg }\end{array}$ & $\begin{array}{c}\text { Diabetic } \\
\text { Retinopathy }\end{array}$ & $\begin{array}{c}\text { Diabetic } \\
\text { Retinopathy }\end{array}$ & Benar \\
\hline 22 & $\begin{array}{c}\text { ID0754036- } \\
\text { 17477.jpg }\end{array}$ & $\begin{array}{c}\text { Diabetic } \\
\text { Retinopathy }\end{array}$ & $\begin{array}{c}\text { Diabetic } \\
\text { Retinopathy }\end{array}$ & Benar \\
\hline 23 & $\begin{array}{c}\text { ID0756895- } \\
\text { 2733.jpg }\end{array}$ & $\begin{array}{c}\text { Diabetic } \\
\text { Retinopathy }\end{array}$ & $\begin{array}{c}\text { Diabetic } \\
\text { Retinopathy }\end{array}$ & Benar \\
\hline 24 & $\begin{array}{c}\text { ID0756895- } \\
\text { 2734.jpg }\end{array}$ & $\begin{array}{c}\text { Diabetic } \\
\text { Retinopathy }\end{array}$ & $\begin{array}{c}\text { Diabetic } \\
\text { Retinopathy }\end{array}$ & Benar \\
\hline 25 & $\begin{array}{c}\text { ID0756895- } \\
\text { 2737.jpg }\end{array}$ & $\begin{array}{c}\text { Diabetic } \\
\text { Retinopathy }\end{array}$ & $\begin{array}{c}\text { Diabetic } \\
\text { Retinopathy }\end{array}$ & Benar \\
\hline 26 & $\begin{array}{c}\text { ID0770768- } \\
\text { 7235.jpg } \\
\end{array}$ & $\begin{array}{c}\text { Diabetic } \\
\text { Retinopathy }\end{array}$ & $\begin{array}{c}\text { Diabetic } \\
\text { Retinopathy }\end{array}$ & Benar \\
\hline 27 & $\begin{array}{c}\text { ID0775111- } \\
\text { 8512.jpg }\end{array}$ & $\begin{array}{c}\text { Diabetic } \\
\text { Retinopathy }\end{array}$ & $\begin{array}{c}\text { Diabetic } \\
\text { Retinopathy }\end{array}$ & Benar \\
\hline 28 & $\begin{array}{c}\text { ID0788109- } \\
\text { 12829.jpg }\end{array}$ & $\begin{array}{c}\text { Diabetic } \\
\text { Retinopathy }\end{array}$ & $\begin{array}{c}\text { Diabetic } \\
\text { Retinopathy }\end{array}$ & Benar \\
\hline 29 & $\begin{array}{c}\text { ID0797354- } \\
\text { 7464.jpg }\end{array}$ & $\begin{array}{c}\text { Diabetic } \\
\text { Retinopathy }\end{array}$ & $\begin{array}{c}\text { Diabetic } \\
\text { Retinopathy }\end{array}$ & Benar \\
\hline 30 & $\begin{array}{c}\text { ID0797354- } \\
\text { 7465.jpg } \\
\end{array}$ & $\begin{array}{c}\text { Diabetic } \\
\text { Retinopathy }\end{array}$ & $\begin{array}{c}\text { Diabetic } \\
\text { Retinopathy }\end{array}$ & Benar \\
\hline
\end{tabular}

Tabel II merupakan hasil diagnosis data training. Perhitungan persentasi error pada Tabel II adalah sebagai berikut:

$$
\begin{gathered}
\% \text { error }=\frac{\sum \text { data error }}{\sum \text { data seluruhnya }} \times 100 \% \\
\% \text { error }=\frac{1}{30} \times 100 \% \\
\% \text { error }=0.0333 \times 100 \% \\
\% \text { error }=3.33 \%
\end{gathered}
$$

Hasil yang didapatkan memiliki persentasi error yaitu

\begin{tabular}{|c|c|c|c|c|}
\hline \multicolumn{5}{|c|}{ Hasil Perhitungan Error } \\
\hline \multirow{2}{*}{ No } & \multirow{2}{*}{ Nama File } & \multicolumn{2}{|c|}{ Hasil Diagnosa } & \multirow{2}{*}{$\begin{array}{l}\text { Vali- } \\
\text { dasi }\end{array}$} \\
\hline & & Sistem & Rumah sakit & \\
\hline 1 & $\begin{array}{c}\text { ID0729496- } \\
\text { 11704.jpg }\end{array}$ & $\begin{array}{c}\text { Diabetic } \\
\text { Retinopathy }\end{array}$ & Normal & Salah \\
\hline 2 & $\begin{array}{c}\text { ID1092734- } \\
\text { 12389.jpg }\end{array}$ & $\begin{array}{c}\text { Diabetic } \\
\text { Retinopathy }\end{array}$ & Normal & Salah \\
\hline 3 & $\begin{array}{c}\text { ID01222814- } \\
\text { 12441.jpg }\end{array}$ & $\begin{array}{c}\text { Diabetic } \\
\text { Retinopathy }\end{array}$ & Normal & Salah \\
\hline 4 & $\begin{array}{c}\text { ID01260484- } \\
\text { 15763.jpg }\end{array}$ & $\begin{array}{c}\text { Diabetic } \\
\text { Retinopathy }\end{array}$ & Normal & Salah \\
\hline 5 & $\begin{array}{c}\text { ID0785163- } \\
\text { 11840.jpg }\end{array}$ & $\begin{array}{c}\text { Diabetic } \\
\text { Retinopathy }\end{array}$ & Normal & Salah \\
\hline 6 & $\begin{array}{c}\text { ID0794788- } \\
\text { 14580.jpg }\end{array}$ & Normal & Normal & Benar \\
\hline 7 & $\begin{array}{c}\text { ID0797191- } \\
\text { 16008.jpg }\end{array}$ & Normal & Normal & Benar \\
\hline 8 & $\begin{array}{c}\text { ID0797701- } \\
\text { 15586.jpg }\end{array}$ & Normal & Normal & Benar \\
\hline 9 & $\begin{array}{c}\text { ID0797977- } \\
\text { 15686.jpg }\end{array}$ & Normal & Normal & Benar \\
\hline 10 & $\begin{array}{c}\text { ID0798657- } \\
\text { 15837.jpg }\end{array}$ & Normal & Normal & Benar \\
\hline 11 & $\begin{array}{c}\text { ID0799893- } \\
\text { 16183.jpg }\end{array}$ & Normal & Normal & Benar \\
\hline 12 & $\begin{array}{c}\text { ID1256814- } \\
\text { 15317.jpg }\end{array}$ & Normal & Normal & Benar \\
\hline 13 & $\begin{array}{c}\text { ID1263234- } \\
\text { 15843.jpg }\end{array}$ & Normal & Normal & Benar \\
\hline 14 & $\begin{array}{c}\text { ID1264974- } \\
\text { 15994.jpg }\end{array}$ & Normal & Normal & Benar \\
\hline 15 & $\begin{array}{c}\text { ID0792027- } \\
\text { 16204.jpg }\end{array}$ & Normal & Normal & Benar \\
\hline 16 & $\begin{array}{c}\text { ID0759328- } \\
\text { 3397.jpg }\end{array}$ & $\begin{array}{c}\text { Diabetic } \\
\text { Retinopathy }\end{array}$ & $\begin{array}{c}\text { Diabetic } \\
\text { Retinopathy }\end{array}$ & Benar \\
\hline 17 & $\begin{array}{c}\text { ID0759328- } \\
\text { 3398.jpg }\end{array}$ & $\begin{array}{c}\text { Diabetic } \\
\text { Retinopathy }\end{array}$ & $\begin{array}{c}\text { Diabetic } \\
\text { Retinopathy }\end{array}$ & Benar \\
\hline 18 & $\begin{array}{c}\text { ID0770768- } \\
\text { 7241.jpg }\end{array}$ & $\begin{array}{c}\text { Diabetic } \\
\text { Retinopathy }\end{array}$ & $\begin{array}{c}\text { Diabetic } \\
\text { Retinopathy }\end{array}$ & Benar \\
\hline 19 & $\begin{array}{c}\text { ID0775439- } \\
\text { 8416.jpg }\end{array}$ & $\begin{array}{c}\text { Diabetic } \\
\text { Retinopathy }\end{array}$ & $\begin{array}{c}\text { Diabetic } \\
\text { Retinopathy }\end{array}$ & Benar \\
\hline 20 & $\begin{array}{c}\text { ID0775939- } \\
\text { 9213.jpg }\end{array}$ & $\begin{array}{c}\text { Diabetic } \\
\text { Retinopathy }\end{array}$ & $\begin{array}{c}\text { Diabetic } \\
\text { Retinopathy }\end{array}$ & Benar \\
\hline 21 & $\begin{array}{c}\text { ID0775939- } \\
9214 . j p\end{array}$ & $\begin{array}{c}\text { Diabetic } \\
\text { Retinopathy }\end{array}$ & $\begin{array}{c}\text { Diabetic } \\
\text { Retinopathy }\end{array}$ & Benar \\
\hline 22 & $\begin{array}{c}\text { ID0785331- } \\
\text { 11740.jpg }\end{array}$ & $\begin{array}{c}\text { Diabetic } \\
\text { Retinopathy }\end{array}$ & $\begin{array}{c}\text { Diabetic } \\
\text { Retinopathy }\end{array}$ & Benar \\
\hline 23 & $\begin{array}{c}\text { ID0785331- } \\
\text { 11741.jpg }\end{array}$ & $\begin{array}{c}\text { Diabetic } \\
\text { Retinopathy }\end{array}$ & $\begin{array}{c}\text { Diabetic } \\
\text { Retinopathy }\end{array}$ & Benar \\
\hline
\end{tabular}
$3,33 \%$ pada tabel II.

TABEL III

Hasil Perhitungan ERror Data Testing 


\begin{tabular}{|c|c|c|c|c|}
\hline 24 & $\begin{array}{c}\text { ID0785665- } \\
\text { 16191.jpg }\end{array}$ & $\begin{array}{c}\text { Diabetic } \\
\text { Retinopathy }\end{array}$ & $\begin{array}{c}\text { Diabetic } \\
\text { Retinopathy }\end{array}$ & Benar \\
\hline 25 & $\begin{array}{c}\text { ID0787823- } \\
\text { 12736.jpg }\end{array}$ & $\begin{array}{c}\text { Diabetic } \\
\text { Retinopathy }\end{array}$ & $\begin{array}{c}\text { Diabetic } \\
\text { Retinopathy }\end{array}$ & Benar \\
\hline 26 & $\begin{array}{c}\text { ID0793528- } \\
\text { 14499.jpg }\end{array}$ & Normal & $\begin{array}{c}\text { Diabetic } \\
\text { Retinopathy }\end{array}$ & Salah \\
\hline 27 & $\begin{array}{c}\text { ID0791941- } \\
\text { 15939.jpg }\end{array}$ & $\begin{array}{c}\text { Diabetic } \\
\text { Retinopathy }\end{array}$ & $\begin{array}{c}\text { Diabetic } \\
\text { Retinopathy }\end{array}$ & Benar \\
\hline 28 & $\begin{array}{c}\text { ID0797073- } \\
\text { 15289.jpg }\end{array}$ & $\begin{array}{c}\text { Diabetic } \\
\text { Retinopathy }\end{array}$ & $\begin{array}{c}\text { Diabetic } \\
\text { Retinopathy }\end{array}$ & Benar \\
\hline 30 & $\begin{array}{c}\text { ID0743256- } \\
\text { 15955.jpg }\end{array}$ & $\begin{array}{c}\text { Diabetic } \\
\text { Retinopathy }\end{array}$ & $\begin{array}{c}\text { Diabetic } \\
\text { Retinopathy }\end{array}$ & Benar \\
\hline
\end{tabular}

Tabel III merupakan hasil dar diagnose data testing. Persentase error yang terjadi pada diagnosis data testing dihitung dengan persamaan berikut:

$$
\begin{gathered}
\% \text { error }=\frac{\sum \text { data error }}{\sum \text { data seluruhnya }} \times 100 \% \\
\% \text { error }=\frac{6}{30} \times 100 \% \\
\% \text { error }=0.2 \times 100 \% \\
\% \text { error }=20 \%
\end{gathered}
$$

Hasil dari keseluruhan data yang sudah dilakukan proses pengujian dengan 60 data uji menghasilkan rata-rata sebagai berikut:

$$
\begin{gathered}
\text { \%error }=\frac{\sum \text { data error }}{\sum \text { data seluruhnya }} \times 100 \% \\
\% \text { error }=\frac{7}{60} \times 100 \% \\
\% \text { error }=0.116 \times 100 \% \\
\% \text { error }=11.6 \%
\end{gathered}
$$

Perhitungan persentase error senilai $11.6 \%$ maka dapat didefinisikan bahwa keberhasilan sistem rata-rata diperoleh dari $100 \%$ keberhasilan sistem dikurangi dengan persentase error yang sudah didapatkan. Maka, persentasi keberhasilan sistem sebesar $88.4 \%$.

Sistem dapat memprediksi dengan 30 data termasuk diabetic retinopathy dari 60 data total. Namun terdapat 2 data yang tidak sesuai dengan klasifikasi yang divalidasi oleh dokter. Perhitungan nilai presisi dengan persamaan matematika (2) sebagai berikut:

$$
\text { Precision }=\frac{T P}{T P+F P} \times 100 \%
$$

Perhitungan nilai presisi sistem dalam mendeteksi adanya diabetic retinopathy dilakukan dengan persamaan matematika (2) sebagai berikut:

$$
\begin{aligned}
& \text { Precision }=\frac{29}{29+6} \times 100 \% \\
& \text { Precision }=\frac{29}{35} \times 100 \% \\
& \text { Precision }=\frac{29}{35} \times 100 \% \\
& \text { Precision }=0.82 \times 100 \% \\
& \text { Precision }=82 \%
\end{aligned}
$$

Hasil perhitungan nilai presisi tersebut sebesar $82 \%$.

\section{KESIMPULAN}

Sistem yang dibangun dengan tahapan-tahapan yang telah diproses menghasilkan nilai akurasi sistem sebesar $88.4 \%$ dan nilai presisi sebesar $82 \%$. Semua tahapan untuk mendeteksi microaneurysm telah dapat dilakukan sehingga sistem menghasilkan klasifikasi 2 kelas, yaitu citra normal dan citra diabetic retinopathy. Penelitian ini perlu dikembangkan untuk memperoleh sistem yang lebih baik dan sempurna. Sistem memerlukan metode-metode yang lebih efisien serta dapat menghilangkan pembuluh darah dengan baik sehingga akurasi sistem lebih besar dan akurat. Dengan demikian, untuk penelitian selanjutnya perlu dilakukan perbaikan parameter yang digunakan untuk memperoleh hasil yang lebih baik dan akurat.

\section{UCAPAN TERIMA KASIH}

Ucapan terima kasih sebesar-besarnya diucapkan kepada semua pihak yang membantu penelitian ini dan juga PENS yang telah mendukung riset ini.

\section{DAFTAR PUSTAKA}

[1] D. Susetianingtias, S. Madenda, Rodiah and Fitrianingsih, "Pengolahan Citra Fundus Diabetik Retinopati Edisi 1," in Pengolahan Citra Fundus Diabetik Retinopati Edisi 1, Jakarta, Gunadarma, 2017.

[2] A. S. Kartasasmita, "Kementrian Kesehatan Republik Indonesia," 2018. [Online]. Available: http://www.yankes.kemkes.go.id/readretinopati-diabetik-pergeseran-paradigma-kebutaan-pada-eramilenial-5984.html. [Accessed 14 may 2020].

[3] N. Das, N. Puhan and R. Panda, "Entropy Thresholding based Microaneurysm Detection in Fundus Images," Jurnal IEEE, 2015.

[4] S. Kumar and B. Kumar, "Diabetic Retinopathy Detection by Extracting Area and Number of Microaneurysm from Colour Fundus Images," 5th International Conference on Signal Processing and Integrated Networks (SPIN Prosiding), pp. 359-364, 2018.

[5] S. S. Puranik and S. Malode, "Morphology Based Approach for Microaneurysm Detection from Retinal Image," International Conference on Automatic Control and Dynamic Optimization Techniques Prociding, pp. 635-639, 2016.

[6] C. Chen, L. Harries, A. C. Kopel, B. L. Lee, P. C. Salmonsen and A. H. Shaikh, "Houston Eye Associates," Glacial Multimedia, [Online]. Available: https:/www.houstoneye.com/retinal-disordershouston/diabetic-retinopathy/. [Accessed 20 july 2020].

[7] M. Santoso, T. Indriyani and R. E. Putra, "deteksi Microaneurysm pada Citra Retina Mata Menggunakan matched filter," Jurnal INTEGER, vol. ii, no. 2, pp. 59-68, 2017.

[8] S. Ozturk and B. Akdemir, "Application of Feature Extraction and Classification Methods for Histopathological Image using GLCM, LBP, LBGLCM,GLRLM and SFTA," Science Direc Papert, pp. 4046, 2018.

[9] P. M. Kumar, P. K. Singh and D. Yada, "GLCM Based Feature Extraction and Medical X-RAY Image Classification using Machine Learning Techniques," Jurnal IEEE, 2019.

[10] Opencv, "Opencv Tutorial," OPENCV, [Online].

[11] Available:

https://docs.opencv.org/4.5.2/d9/d61/tutorial_py_morphological_ops. html. [Accessed 29 June 2021].

[12] I. M. Parapat, M. T. Furqon and Sutrisno, "Penerapan Metode Support Vector Machine (SVM) Pada Klasifikasi Penyimpangan Tumbuh Kembang Anak," Jurnal Pengembangan Teknologi Informasi dan Ilmu Komputer, vol. ii, no. 10, pp. 3163-3169, 2018. 